\title{
Axo-Glial Interactions at the Dorsal Root Transitional Zone Regulate Neurofilament Protein Synthesis in Axotomized Sensory Neurons
}

\author{
Francis J. Liuzzi and Bruce Tedeschi \\ Department of Anatomy and Neurobiology, Eastern Virginia Medical School, Norfolk, Virginia 23501
}

\begin{abstract}
After dorsal root crush, dramatic ultrastructural differences are observed between regenerated dorsal root axonal endings that are physically blocked at a ligation neuroma and those that are allowed to form axo-glial endings among the astrocytes at the dorsal root transitional zone (DRTZ). Physically blocked axonal endings swell immensely with membranous organelles and neurofilaments (NFs) while axo-glial endings do not, suggesting that DRTZ astrocytes stop axonal growth by activating a physiological stop pathway within those endings. Since protease-dependent NF degradation at axonal endings is a part of this pathway, this study addresses the question of whether NF subunit synthesis in the dorsal root ganglion (DRG) is regulated by the pathway. Lumbar dorsal roots were crushed and, at various postinjury times, the attached DRGs were removed and pulse-labeled in vitro with ${ }^{35}$ S-methionine for subsequent analysis of protein synthesis by electrophoresis and fluorography. Within $24 \mathrm{hr}$ of axotomy, there was a down-regulation of the $68 \mathrm{kDa}$ (NF-L) and $145 \mathrm{kDa}$ (NF-M) NF subunits. At $14 \mathrm{~d}$ postcrush, a time when most of the regenerating axons have reached and been stopped by DRTZ astrocytes, NF protein synthesis returned to control levels. By contrast, when the axons were prevented from reaching the DRTZ by ligating or removing segments of the roots, NF synthesis failed to return to normal levels. These data suggest that activation of the physiological stop pathway by DRTZ astrocytes regulates NF protein synthesis in the DRG.
\end{abstract}

Following CNS injury in adult mammals, axonal regeneration is typically abortive, yet when provided a suitable, growth-permissive terrain such as a PNS graft, adult CNS neurons are able to extend axons over long distances (David and Aguayo, 1981; Richardson et al., 1984), and if provided target tissue, these axons stop and synapse (Vidal-Sanz et al., 1987). These observations indicate that adult CNS neurons are intrinsically capable of regenerating their axons and are responsive to growth-promoting molecules within the supportive PNS environment. $\Lambda$ bortive CNS regeneration, then, is not primarily the result of lost neuronal growth potential but rather a consequence of a cellular environment that is either nonsupportive (Liesi, 1985)

\footnotetext{
Received Apr. 21, 1992; revised June 19, 1992; accepted June 29, 1992.

This work was supported by grants from the NIH (NS24309), the Spinal Cord Research Foundation, and the Jeffress Foundation. We are indebted to Sandra Kohler and James Slusser for their technical assistance and Dr. Jean M. LeBeau for her critical reading of the manuscript.

Correspondence should be addressed to Francis J. Liuzzi, Department of Anatomy and Neurobiology, Eastern Virginia Medical School, P.O. Box 1980, 700 Olney Road, Norfolk, VA 23501.

Copyright (C) 1992 Society for Neuroscience $0270-6474 / 92 / 124783-10 \$ 05.00 / 0$
}

or actively inhibitory (Schwab and Caroni, 1988; Schnell and Schwab, 1990) to axonal growth.

Adult mammalian dorsal root ganglion (DRG) neurons and their central axons, which have extensive CNS projections, afford an advantageous in vivo model to study the regulation of axonal growth by the CNS cellular environment (Carlstedt, 1985; Liuzzi and Lasek, 1987a; Reier and Houle, 1988). Following crush injury, dorsal root axons regenerate vigorously through the PNS environment of the root until they reach the dorsal root transitional zone (DRTZ), a PNS-CNS interface. Astrocytes on the CNS side of this interface, in response to dorsal root injury, form a typical glial scar composed of tightly interwoven glial processes (Liuzzi and Lasek, 1987a; Reier and Houle, 1988).

The majority of the regenerating dorsal root axons stop among these astrocytic processes and form stable axo-glial endings (Liuzzi and Lasek, 1987a; Stensaas et al., 1987). Those few axons that are not stopped at the DRTZ either penetrate into the spinal cord (Liuzzi and Lasek, 1987b) or grow back toward the DRG. Since there is no direct trauma to the spinal cord, the effects of a purely astrocytic environment on axon growth can be studied independent of vascular injury and connective tissuc scarring (Carlstedit, 1985; Liuzzi and Lasek, 1987a).

Ultrastructural analyses of axo-glial endings at the DRTZ following dorsal root crushes in adult rats demonstrate that the stopped axon tips display characteristics similar to those of normal presynaptic terminals (Liuzzi and Lasek, 1987a; Stensaas et al., 1987). The axo-glial endings have diameters similar to normal presynaptic endings and contain modest numbers of cytoplasmic organelles such as mitochondria and small vesicles. Moreover, like normal presynaptic endings, there are no neurofilaments (NFs) within the axo-glial endings (Liuzzi and Lasek, 1987a).

This ultrastructural morphology is unlike that of physically blocked axonal endings observed at ligation neuromas (Liuzzi and Lasek, 1987a; Liuzzi, 1990b; Fried et al., 1991). Physically blocked endings are large in comparison to axo-glial endings at the DRTZ and are particularly noteworthy for massive accumulations of membranous organelles and NFs. These morphological data suggest that DRTZ astrocytes and the glial scar they form are not a mere physical barrier to axonal growth but rather actively stop growth by regulating events within the axonal endings (Liuzzi and Lasek, 1987a; Liuzzi, 1990a). This regulation of axonal growth has been termed the physiological stop pathway by Liuzzi and Lasek (1987a) and is presumed to be the same mechanism by which appropriate targets stop axonal growth

It is not known fully what regulatory events in neurons underlie the physiological stop pathway or how target cells mediate 
Figure 1. Diagrammatic representation of the four kinds of dorsal root manipulations conducted in this study. In $A$ (control), dorsal roots were not crushed in the surgically operated animals $(N=5)$. DRGs contralateral to injured dorsal roots were not used as controls in this study due to contralateral effects on DRG protein synthesis (M. M. Oblinger, personal communication). In $B$ (crush), dorsal roots were crushed and regenerating axons were allowed to reach the DRTZ. In $C$ (crushligation), dorsal roots were crushed and a suture ligation was created between the injury and the DRTZ. In $D$ (cut), dorsal roots were prevented from reaching the DRTZ by removal of a 2 $\mathrm{mm}$ segment of the root.

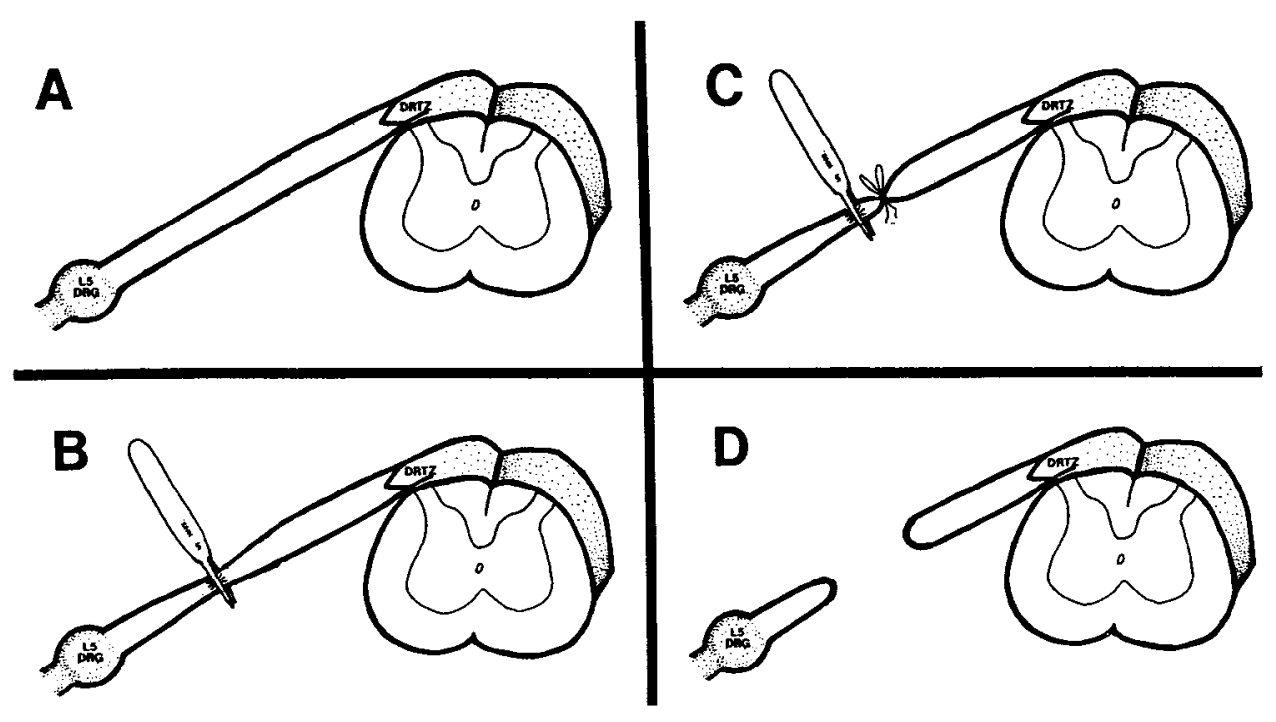

their effects on this pathway. The marked ultrastructural differences between physiologically stopped axonal endings, whether by normal targets or DRTZ astrocytes, and those stopped by mechanical barriers indicate that normal targets, and in the case of the DRTZ, astrocytes, regulate important posttranslational events at axonal endings. Indeed, it has recently been shown that NF breakdown is a protease-dependent event in axo-glial endings at the DRTZ (Liuzzi, 1990a), as it is in normal presynaptic endings (Roots, 1983). Since there is considerable evidence that events at the ends of axons profoundly affect metabolic processes back at the cell body, the present study addresses the question of whether NF protein synthesis in the DRG is regulated by activation of the physiological stop pathway by astrocytes in the DRTZ.

\section{Materials and Methods}

\section{Animals and surgical procedures}

Fifty-four adult female Lewis rats (Harlan Sprague-Dawley) weighing an average of $250 \mathrm{gm}$ at the time of surgery were used in this study. All animals were obtained, cared for, and surgically handled in accordance with the guidelines specified in the NIH Guide for the Care and Use of Laboratory Animals. The rats were anesthetized by an intramuscular injection of a mixture of ketamine $(80 \mathrm{mg} / \mathrm{kg})$ and xylazine $(8 \mathrm{mg} / \mathrm{kg})$. The area over the lumbar spinal column was shaved and thoroughly cleaned. Using aseptic surgical procedures, the skin and muscle over the L2 and L 3 vertebrae were incised longitudinally, and a laminectomy was performed at this level. The dura was longitudinally slit, and the three largest-diameter dorsal roots at that level (typically L3, L4, and L5) were carefully exposed using a fine dural hook. Control animals (Fig. 1A) had no further manipulations. Crushes (Fig. 1B) were made using a \#5 Dumont jewclers forcep. Each root was crushed individually, twice in the same place for $20 \mathrm{sec}$ each time. In the crush-ligation condition (Fig. 1C), the crushes were made in the same way, after which the roots were tightly ligated with 6-0 silk between the crush site and the spinal cord, $2 \mathrm{~mm}$ distal to the crush site. In the cut condition (Fig. $1 D$ ), the roots had a $2 \mathrm{~mm}$ segment removed from the same portion of the roots that were crushed in the other conditions. The crushes or cuts were consistently in the same place. For the L5 dorsal root, the distance from the crush or cut site to the DRTZ was approximately $10 \mathrm{~mm}$. The cords were then covered with sterile Gelfoam, the muscle and skin closed in layers, and the animals returned to their home cages.

At various times from 1 to $90 \mathrm{~d}$ after surgery, the animals were reanesthetized; the operated dorsal roots with their attached ganglia were exposed and their identities verified based on the locations of the ganglia. For the prescnt study, only the L5 ganglion, located in the intervertebral foramen, between the L5 and L6 vertebrae, was used. The ganglion from the operated side, with 1-3 mm segments of spinal nerve and dorsal root attached, was removed and placed in Dulbecco's Modified Eagles Media (DMEM; GIBCO, Grand Island, NY).

\section{Radiolabeling of DRG polypeptides}

Each DRG was desheathed, and proteins radiolabeled by incubation of each DRG at $37^{\circ} \mathrm{C}$ for $1 \mathrm{hr}$ in $50 \mu$ l oxygenated $\left(95 \% \mathrm{O}_{2}\right)$ methioninefree DMEM supplemented with $100 \mu \mathrm{Ci}{ }^{35} \mathrm{~S}$-methionine $(\sim 1000 \mathrm{Ci} /$ $\mathrm{mmol}$; Dupont-New England Nuclear). Following the $1 \mathrm{hr}$ in vitro incubation period, each DRG was immediately rinsed in standard DMEM (supplemented 10-fold with unlabeled methionine) and visually stripped of all attached nerve segments.

\section{Sample preparation for $2 D-P A G E$}

All procedures were performed at $4^{\circ} \mathrm{C}$. Individual DRGs were homogenized in small glass grinders containing $1.0 \%$ sodium dodecyl sulfate (SDS-United States Biochemical Comp.), 10\% 2-mercaptoethanol, and $8 \mathrm{M}$ urea (Ultra-Pure, Schwarz-Mann) in a total volume of $14 \mu \mathrm{l}$. The homogenate was transferred to a microcentrifuge tube containing $5 \mu \mathrm{l}$ O'Farrell's (1975) lysis supplement (ampholines 4-6, 5-7, and 3-10 in 2:2:1 ratio) with $4 \mu \mathrm{g}$ of urea. The grinders were then washed twice (10 $\mu \mathrm{l}$ each) with O'Farrell's (1975) lysis buffer (9.5 M urea, $2 \%$ NP-40, 5\% mercaptoethanol, and $2.0 \%$ ampholytes). Samples were clarified by ultracentrifugation $(35,000 \mathrm{rpm}, 60 \mathrm{~min})$, and the supernatant was transferred to a clean tube on ice. For determination of acid-precipitable radioactivity, an aliquot $(1 \mu \mathrm{l})$ of each sample homogenate was added to $10 \%$ trichloroacetic acid; the precipitate was collected by centrifugation $(10,000 \mathrm{rpm}, 10 \mathrm{~min})$ and solubilized in scintillation counting fluid (containing $80 \%$ toluene, 9\% NCS (Amersham), $4 \mathrm{~m}$ ammonium hydroxide, and $9 \%$ concentrated $(10 \times)$ diphenyloxasole/1,4 bis[2-\{5phenyloxazolyl $\}]$ benzene), and $\mathrm{cpm}$ was determined by counting (20 $\mathrm{min} / \mathrm{sample}$ ) in a Beckman LS-7000 liquid scintillation spectrophotometer. Samples containing equal amounts of acid-precipitable cpm $(250,000)$ were loaded onto the first-dimensional gels.

\section{D-PAGE and fluorography}

Sample polypeptides were separated in the first dimension by isoelectric focusing (IEF). The ampholytes (4-6, 5-7, 3-10 in 2:2:1 ratio) in IEF tube gels were from Bio-Rad Corp., and gels were run for $8000 \mathrm{~V} / \mathrm{hr}$ $(400 \mathrm{~V} / 15 \mathrm{hr}$ followed by $1000 \mathrm{~V} / 2 \mathrm{hr}$ ). Gels were extruded by positive pressure, equilibrated (30 min) in $2.3 \%$ SDS (O'Farrell's SDS sample buffer), and carefully applied to the top of a precast gel for SDS-polyacrylamide electrophoresis. The stacking gel contained $4.5 \%$ polyacrylamide, while the separating gel contained $10 \%$ polyacrylamide $(29.2$ : 0.8 acrylamide:bis-acrylamide ratio in all cases). Previous studies have shown that the resolvable $2 \mathrm{D}$ window, under these conditions, is $\sim 15-$ $200 \mathrm{kDa}$ in the molecular weight dimension and $\sim 4.0-8.0$ in the isoclcctric dimension (Wilson ct al., 1977; Tcdeschi and Wilson, 1983, 1987). Following electrophoresis, gels were fixed and stained by immersion $(15 \mathrm{~min})$ in $25 \%$ trichloroacetic acid (containing $0.1 \%$ Coom- 
assie brilliant blue $\mathrm{R}$ ) and destained by several washes in 7\% acetic acid. The position of known proteins in the Coomassie-stained gel allowed an initial assessment as to the success of the $2 \mathrm{D}$ separation. The gels were then embedded with the fluor diphenyoxasole (Bonner and Laskey, 1974; Laskey and Mills, 1975), vacuum-dried at $60^{\circ} \mathrm{C}$ against filter paper, and used to expose Kodak XAR-5 film for varying periods at $-70^{\circ} \mathrm{C}$.

\section{Quantification of $N F$ subunit synthesis}

Procedures utilizing the gel cutout method of quantification have been previously described (Wilson et al., 1977; Tedeschi and Wilson, 1983, 1987). Briefly, the fluorographs were used as templates to cut out specific radiolabeled polypeptide spots from each gel with a scalpel blade. The cutout spots were then placed in vials, containing toluene-based liquid scintillation counting fluid, and shook for $24 \mathrm{hr}$. Each sample was counted in the liquid scintillation spectrophotometer for $20 \mathrm{~min}$. Spots corresponding to the $68 \mathrm{kDa}(\mathrm{NF}-\mathrm{L})$ and $145 \mathrm{kDa}(\mathrm{NF}-\mathrm{M}) \mathrm{NF}$ subunits were identified by immunoblotting, using monoclonal antibodies to individual NF subunits from Sternberger Monoclonals and NF-L polyclonal antibodies from ICN/Flow Laboratories. The third NF subunit, the $200 \mathrm{kDa}$ subunit, was not easily identifiable on our gels and was not included in the analysis. In addition to the radiolabeled NF subunits, we also cut out three other unidentified polypeptides from each gel that have previously been shown to demonstrate no change in synthesis following axotomy (Hall, 1982).

\section{Statistical analysis}

Spot normalization within gels. It was assumed that in any particular gel, the ratio of $\mathrm{cpm}_{\mathrm{NF}}$ subunit spot: $\mathrm{cpm}_{\text {added }}$ is a reliable quantitative estimate (given the $1 \mathrm{hr}$ labeling time) of the synthesis of the NF subunit relative to the total DRG protein synthesis. Since equal acid-precipitable $\mathrm{cpm}$ was added to all gels in this study, we computed the raw cpm of the NF subunits between gels. We also used a second normalization to correct for the possibility that one (or more) of the experimental conditions (crush, ligation, cut) may have caused a change (relative to control) in overall DRG protein synthesis. Since such a possibility could create an experimental bias when comparing spot cpm, the second normalization used the cpm of three polypeptide reference spots (see Fig. 2 ), previously shown to demonstrate no statistical change in rat DRG synthesis following nerve injury (Hall, 1982). Thus, the second gel normalization was $\mathrm{cpm}_{\mathrm{NF} \text { subunit spor: }}$ :mean $\mathrm{cpm}_{\text {reference spots. }}$

Comparisons between gels. Each datum in the statistical analysis was the value of a normalized NF subunit spot from a gel. The statistical designs were 2-way repeated-measures analysis of variance for unequal $N s$. The first independent variable in the ANOVA was surgical manipulation with three experimental groups (crush, ligation, and cut) and one control group, while the second independent variable (NF subunit analyzed) was nested within the first independent variable. The data obtained from the four postmanipulation time points $(1,3,14,>30 \mathrm{~d})$ were analyzed in four separate ANOVAs for each normalization procedure. Post hoc analyses of the groups were made by the NeumannKeuls test.

\section{NF Western blot analysis}

One animal in the crush-ligation group, with a postoperative survival time of $30 \mathrm{~d}$, was used for NF Western blot analysis. Equal-length (4 $\mathrm{mm}$ ) segments of the L5 dorsal root, just proximal and just distal to the ligature, were dissected and desheathed, and polypeptides were solubilized by homogenization in a small glass grinder with $50 \mu \mathrm{l}$ of Laemmli sample buffer $(0.0625$ м Tris- $\mathrm{HCl}, \mathrm{pH} 6.8 ; 2 \% \mathrm{SDS} ; 10 \%$ glycerol; $5 \%$ 2-mercaptoethanol; $0.001 \%$ bromophenol blue). Each homogenate was heated at $100^{\circ} \mathrm{C}$ for $5 \mathrm{~min}$ and spun $(10,000 \mathrm{rpm}$ for $10 \mathrm{~min})$, and the supernatant was applied to individual lanes for separation by SDSelectrophoresis in a $10 \%$ polyacrylamide gel. Molecular weight was calibrated by the addition of prestained molecular weight markers (Rainbow markers from Amersham). Following electrophoresis, the separated polypeptides were transferred to a nylon membrane $\left(0.8 \mathrm{~mA} / \mathrm{cm}^{2}\right)$ for $1 \mathrm{hr}$. Nonspecific membrane binding was blocked by $5 \%$ nonfat dry milk (in PBS), and the membrane was incubated with monoclonal antibody specific to a phosphorylated NF epitope (SM31; purchased from Sternberger Monoclonals). Antibody binding to blotted NF was visualized by incubation with alkaline phosphate-conjugated anti-mouse IgG and subsequent visualization by enzymatic reaction with nitroblue tetrazolium and bromochloroindolephosphate in $10 \mathrm{~mm}$ Tris, $\mathrm{pH} 7.4$.

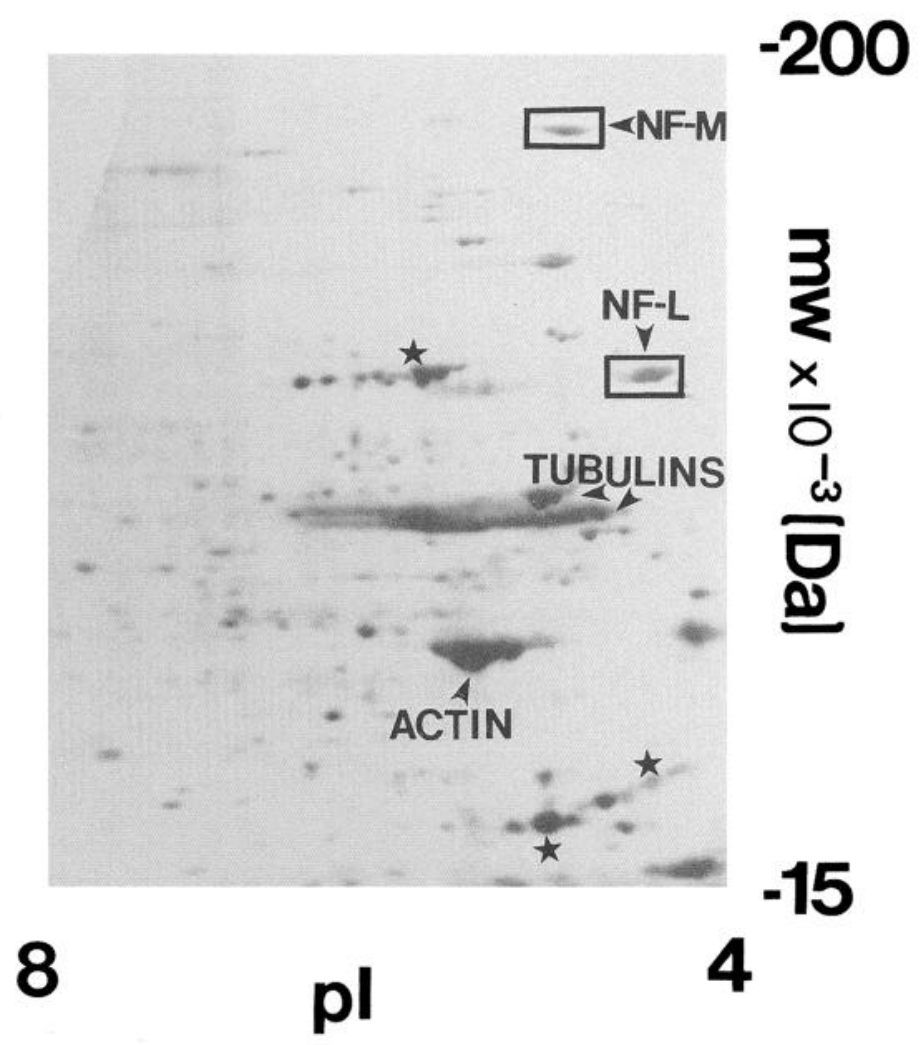

Figure 2. Fluorograph of radiolabeled DRG polypeptides separated by 2D-PAGE. Arrowheads point to some of the major cytoskeletal protein subunits synthesized by DRG. The positions of NF-L and NF-M were previously identified by immunoblots, and they may be represented by circular spots, cigar-shaped smears, or equally spaced multiple spots on the fluorographs. Despite these microheterogeneic posttranslational modifications, which increase (or decrease) the areas of the NF subunits in the isoelectric dimension, the relative positions of the two subunits, with respect to other proteins in the fluorographs, do not change. The rectangles around NF-L and NF-M represent the exact areas of the gel that were excised for subsequent quantification of NF$\mathrm{L}$ and NF-M. The three polypeptides, identified by stars, have previously been shown to demonstrate no significant quantitative changes in synthesis following nerve injury (Hall, 1982). Further fluorographic presentations of NF expression will be limited to the upper right quadrants and exposure to $\mathrm{x}$-ray film will be less since $\mathrm{x}$-ray film can deviate from densitometric linearity with long exposures.

\section{Electron microscopy}

Crush-ligations were performed on two animals, as described above, except that the tissue was processed for electron microscopy. Additionally, cut dorsal roots from two other animals were harvested and processed for electron microscopy. Three weeks after the crush-ligations or 4 weeks after the cuts, the animals were deeply anesthetized and perfused intracardially with a fixative containing $2 \%$ paraformaldehyde and $2 \%$ glutaraldehyde in phosphate buffer. The ligated or cut roots were dissected out and processed by routine methods for electron microscopy and embedded in Maraglas. The roots were embedded with the portion distal to the ligature or the cut end nearest the block surface. Ultrathin cross sections of the roots were cut on a Reichert Ultracut E ultramicrotome, placed on 200 mesh copper grids, and stained with lead citrate and uranyl acetate. Sections of the distal root and ligature site or the cut end were viewed and photographed on a JEOL 1200 transmission electron microscope.

\section{Results}

\section{$2 D$ pattern of radiolabeled polypeptides synthesized by $D R G$}

The fluorograph in Figure 2 shows the typical 2D pattern of polypeptides synthesized by DRG. NF-L and NF-M migrate to the exact relative positions on the $2 \mathrm{D}$ fluorographs as has been 


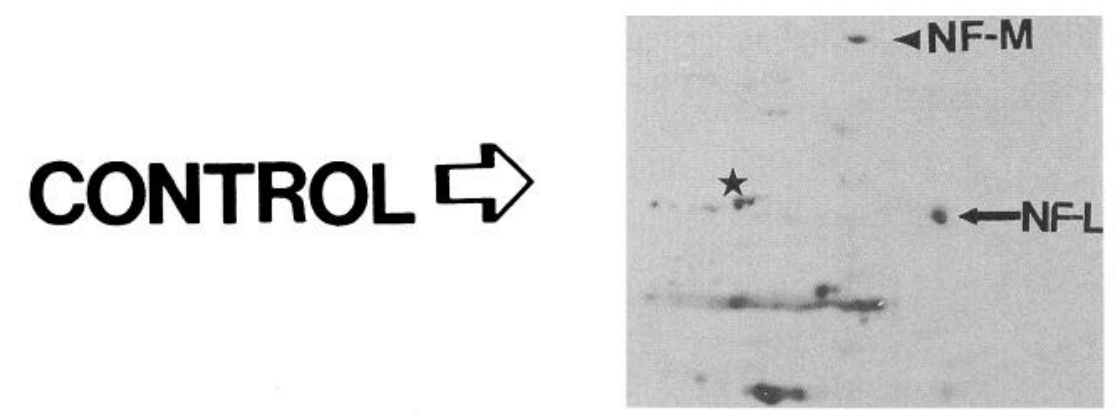

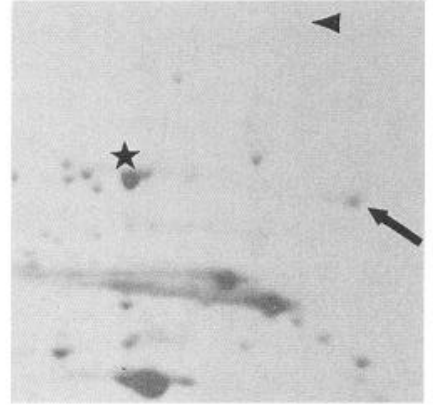

1 Day

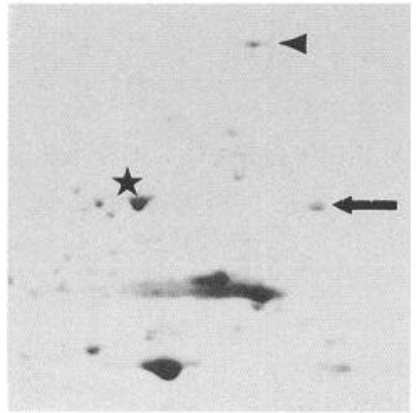

3 Day

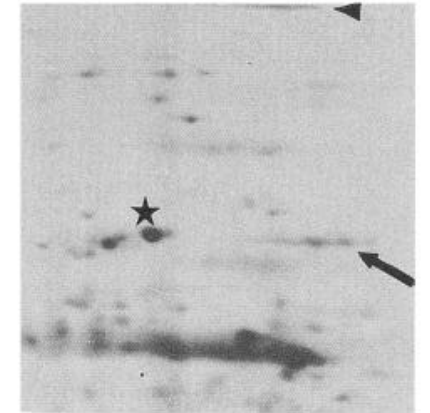

7 Day

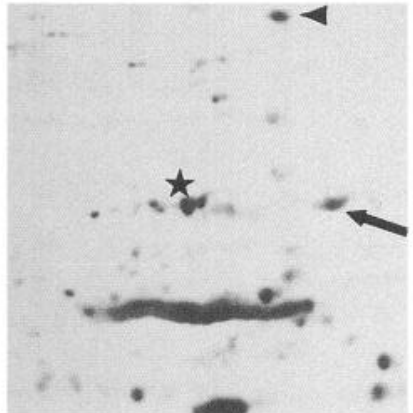

14 Day

\section{CRUSH}

Figure 3. Fluorographs of DRG NF-L and NF-M polypeptide expression at various time points following crush injury. All fluorographs shown had equal acid-precipitable cpm added to each gel. Arrows point to the position of NF-L, and arrowheads point to the position of NF-M. In comparison with control, it can be observed that the radiolabeling of both NF-L and NF-M appears to decrease at $1 \mathrm{~d}$ following crush injury. Further, the apparent density of the two NF subunits remains lower than control at the three earliest postcrush time points (1-7 d). Of these three earliest time points, some recovery toward control is apparent at the $7 \mathrm{~d}$ time point (the isoelectric heterogeneity of the two NF spots in this fluorograph was not a consistent observation). At the $14 \mathrm{~d}$ postcrush time point, the apparent densities of the two NF subunits seemed similar to control. This return to control densities was stable at long-term time points ( $>30 \mathrm{~d}$; fluorographs not shown). The stars indicate in these fluorographs (and all subsequent fluorographs) one of the reference spots, whose synthesis has previously been shown to be statistically unaffected by axotomy (Hall, 1982).

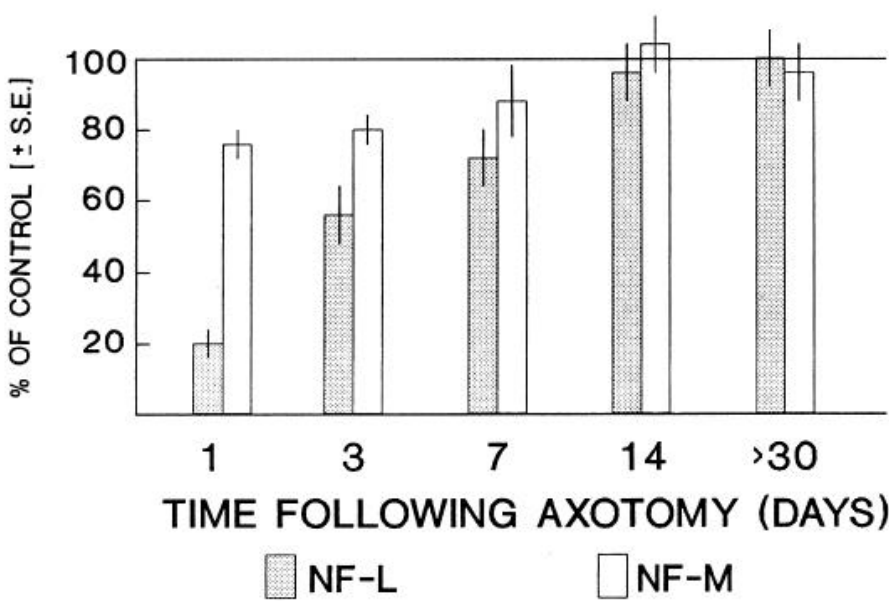

Figure 4. Bar histograph showing the kinetics of the quantitative changes in DRG synthesis of NF subunits following crush injury. The data were tabulated by comparing the cpm of each NF spot and dividing by the mean cpm for that spot in the control condition $(N=5 /$ subunit spot $)$ Thus, the data are expressed in the histograph as a percentage of control (sham-operated) values, with the height of each histogram representing the mean values for each NF subunit at each postinjury time point; reported for these subunits by previous investigators (Oblinger, 1987; Greenberg and Lasek, 1988; Tetzlaff et al., 1988). The identities of these spots were confirmed by use of antibodies to individual NF subunits. In addition to the relative position of the spots, some isoelectric microheterogeneity in both NF-L and NF-M polypeptides has been reported that can create, on 2D gels, either closely spaced multiple spots or a cigar-shaped smear. We also have made this observation in the present study. This microheterogeneity may be due to posttranslational modifications (e.g., phosphorylation) taking place soon after translation. Despite this microheterogeneity, Oblinger (1987) found that both NF-L and NF-M show no large changes in their gel

error bars represent SE. For either NF-L or NF-M, the data points were based on four experimental gels (four animals) at $1 \mathrm{~d}$ postcrush, four experimental gels (four animals) at $3 \mathrm{~d}$ postcrush, three experimental gels (three animals) at $7 \mathrm{~d}$ postcrush, four experimental gels (four animals) at $14 \mathrm{~d}$ postcrush, and three experimental gels (three animals) at $>30 \mathrm{~d}$ postcrush. The quantitative data verify that the DRG synthesis of both NF subunits returns to normal levels by $14 \mathrm{~d}$ postcrush and remains at control levels long-term. 


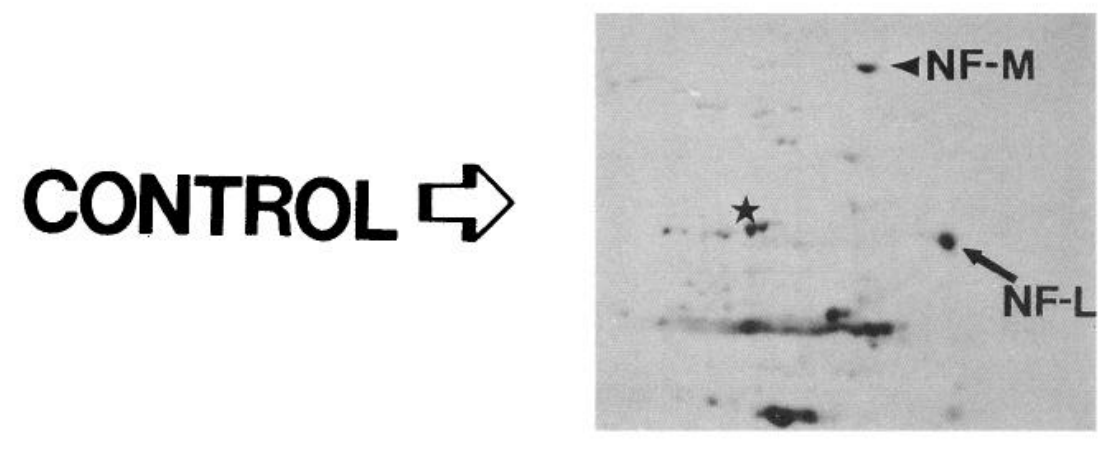

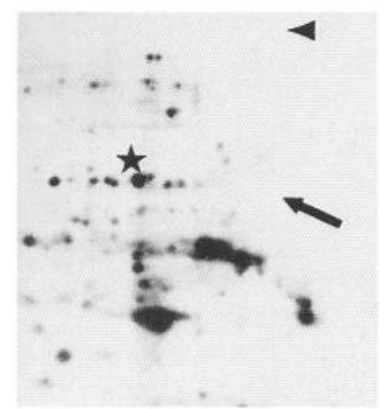

1 Day

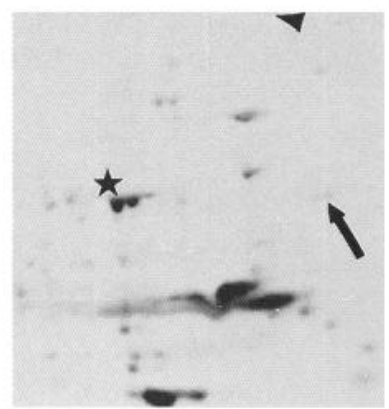

3 Day

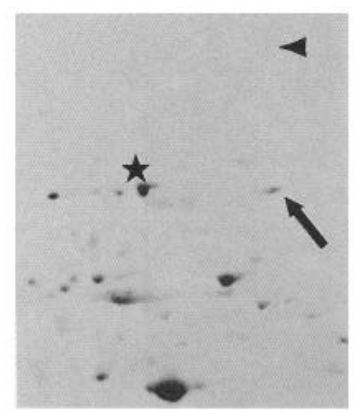

7 Day

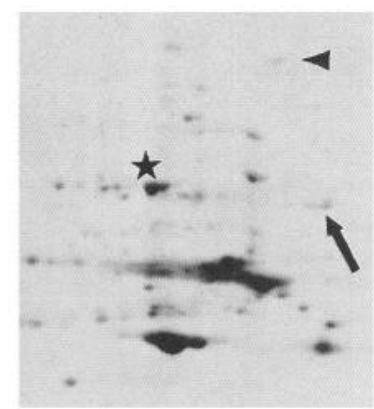

14 Day

\section{CRUSH-LIGATION}

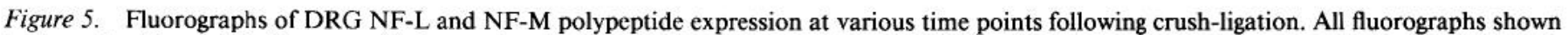

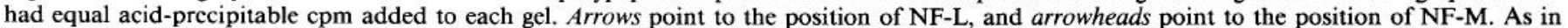

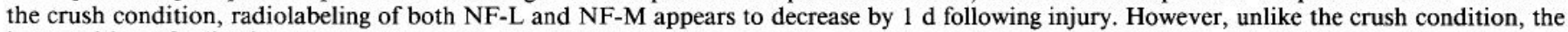

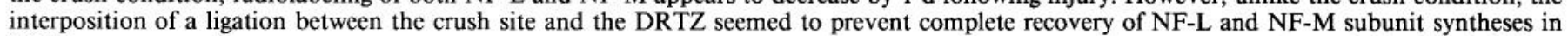
DRG.

positions (due to posttranslational modifications), even at long pulse-chase kinetics.

NF-M appeared as either one spot or a cigar-shaped smear. In all cases, our standard gel excision was large enough to include the spot or the cigar-shaped smear for quantification of NF-M. NF-L usually appeared as a spot or small smear, but occasionally multiple spotting could be discerned. Our standard gel excision of NF-L included a region that encompassed either one spot, a smear, or microheterogeneic multiple spots. We found that the appearance of multiple spots in the NF-L region was random, and therefore the reported results would not have varied even if only one spot in the NF-L gel region was analyzed.

The boxed regions in Figure 2 show the exact regions of the gel that were excised for quantification of NF-L and NF-M. The three polypeptides that were used as the reference spots for the second normalization procedure are identified by stars. Further presentations of the $2 \mathrm{D}$ fluorographs are limited to the upper right quadrant of the fluorographs.

Effects of events at the axonal endings on NF subunit synthesis in $D R G$

Crush group. In the crush group, the regenerated dorsal roots grow through the distal PNS terrain until they are stopped by reactive astrocytes at the DRTZ. The $2 \mathrm{D}$ fluorographs in Figure 3 show changes in the synthesis of DRG polypeptides at various time points following the crush injury. It can be seen that, following the initial decrease in NF subunit synthesis within $24 \mathrm{hr}$ of injury, NF-L and NF-M subunit synthesis eventually recovers to normal, control levels. Visual scanning of the fluorographs suggests that, although there is some recovery in NF subunit syntheses at $7 \mathrm{~d}$ postcrush, complete recovery was attained by $14 \mathrm{~d}$ postcrush. Quantitative analyses of the NF-L and NF-M subunits verify these observations. The bar histogram in Figure 4 shows that DRG subunit synthesis, for both NF-L and NF$\mathrm{M}$, returns to control levels at $14 \mathrm{~d}$ following injury and remains at those levels for all later time points examined ( $>30 \mathrm{~d}$ ). Statistical analyses of the crush data showed that the synthesis of both NF subunits was not significantly different from control at $14 \mathrm{~d}$ and later time points $(p<0.01)$. The same findings were obtained whether the raw cpm data or data normalized by the reference spots were analyzed. Since the distance from the crush site to the spinal cord (L1 spinal segment) for the L5 root was constant at approximately $10 \mathrm{~mm}$ and the rate of dorsal root axonal regeneration is $2.1 \mathrm{~mm} / \mathrm{d}$ (Wujek and Lasek, 1983), the majority of the dorsal root axons should have reached the dorsal root-spinal cord interface between 7 and $14 \mathrm{~d}$ postinjury. Thus, 


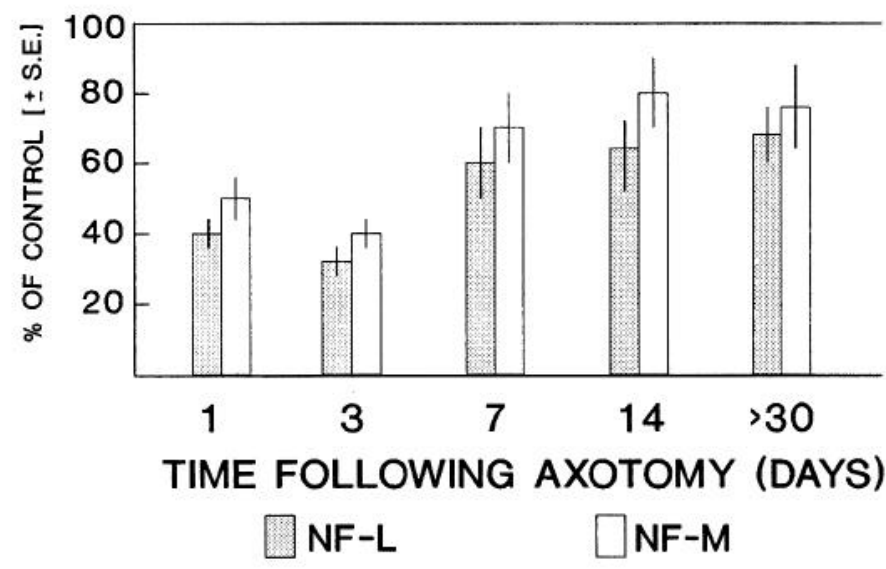

Figure 6. Bar histograph showing the kinetics of the quantitative changes in DRG synthesis of NF subunits in the crush-ligation condition. For either NF-L or NF-M, the data points were based on three experimental gels (three animals) at $1 \mathrm{~d}$ postcrush, three experimental gels (three animals) at $3 \mathrm{~d}$ postcrush, three experimental gels (three animals) at 7 $\mathrm{d}$ postcrush, four experimental gels (four animals) at $14 \mathrm{~d}$ postcrush, and four experimental gels ( 4 animals) at $>30 \mathrm{~d}$ postcrush. Error bars represent SE. The quantitative data verify that the DRG synthesis of both NF subunits never reaches control levels, although some recovery is observed between 1 and $14 \mathrm{~d}$ postinjury.

the upregulation of NF subunit synthesis to control levels is consistent with the time at which the majority of regenerating axons reach the astrocytes of the DRTZ.

Crush-ligation group. In the crush-ligation group, many re- generating dorsal root axons are stopped at a cul-de-sac, created by a ligation made between the crush site and the spinal cord. The 2D fluorographs in Figure 5 show changes in the synthesis of DRG NF subunits at various time points following the crush injury. In this case, the initial decrease in NF subunit synthesis does not appear to be followed by a complete return to control levels. Statistical analyses of the crush-ligation data showed that synthesis of both NF subunits, at all time points following crushligation, was significantly different from control $(p<0.01)$. The bar histogram in Figure 6 shows that DRG NF subunit synthesis does not return to control levels at any postcrush time point. Although there is never complete recovery of normal levels of NF subunit synthesis, there is apparently some partial recovery between $1 \mathrm{~d}$ postcrush and $14 \mathrm{~d}$ postcrush.

To address this partial return toward control levels of NF subunit synthesis, both Western blot analysis using an NF antibody and electron microscopic observations of dorsal roots at and distal to the ligature were done to determine whether regenerating axons were able to grow past the ligature. The results of both approaches are shown in Figure 7. The Western blot analysis shows that NF protein accumulates proximal to the ligature, but there is some NF protein distal. Since $30 \mathrm{~d}$ had passed since the crush and ligation, the NF protein distal to the ligature most likely represents the content of regenerated axons that had grown beyond the ligature rather than that of degenerated axons. The electron microscopic observations confirmed the presence of numerous regenerated axons distal to a dorsal root ligature. Presumably these axons reach the DRTZ. Thus, the partial recovery of NF subunit synthesis could be explained
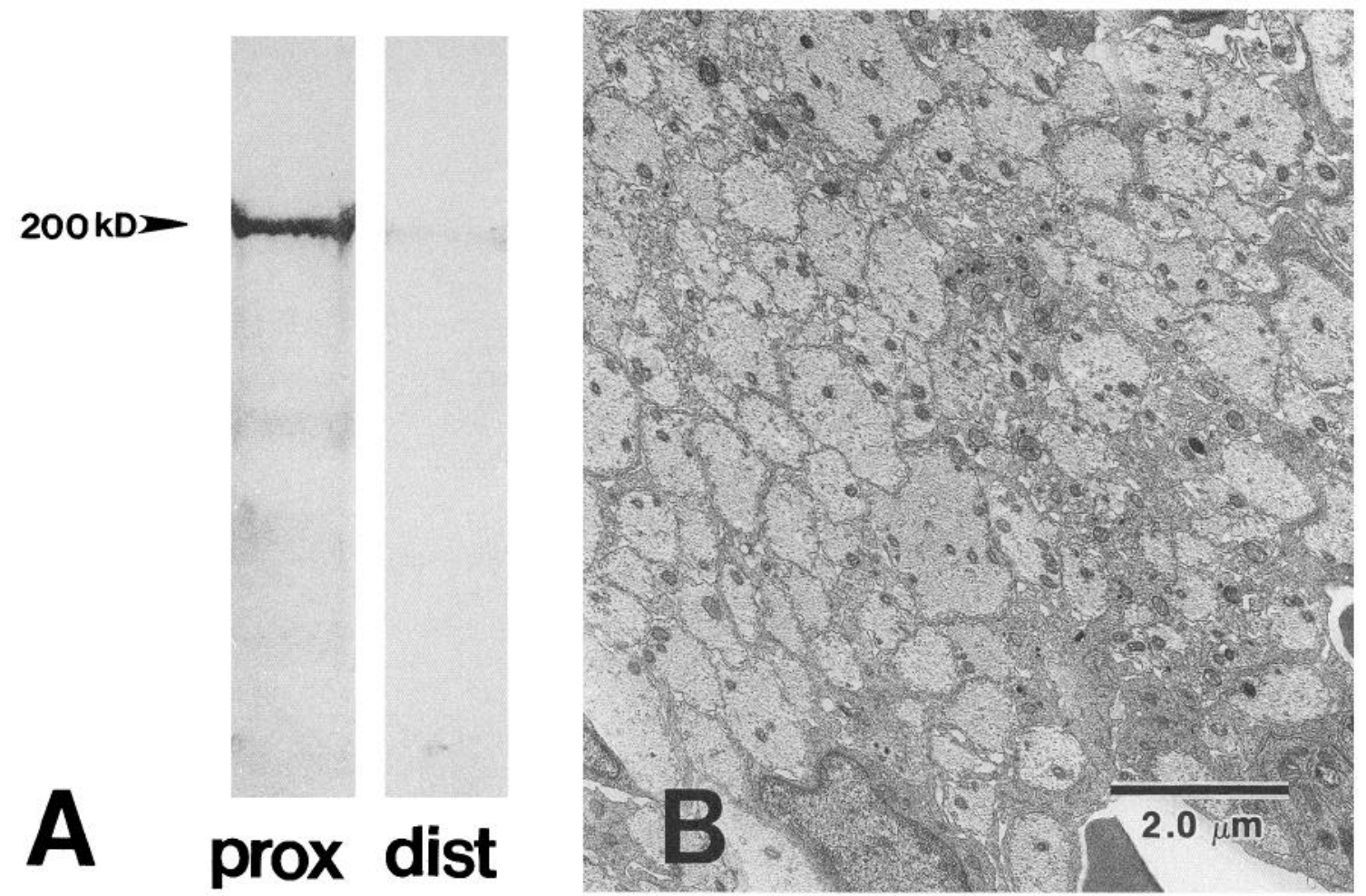

Figure 7. A, Western blot analysis using a monoclonal antibody specific to the phosphorylated NF epitope shows an accumulation of $200 \mathrm{kDa}$ $\mathrm{NF}$ protein proximal to the ligature site and considerably less $200 \mathrm{kDa}$ NF protein distal to the ligature, indicating the presence of axons distal to the ligature. $B$, Electron microscopy of a ligated dorsal root just distal to the ligature shows that many axons grow through the ligature site. 


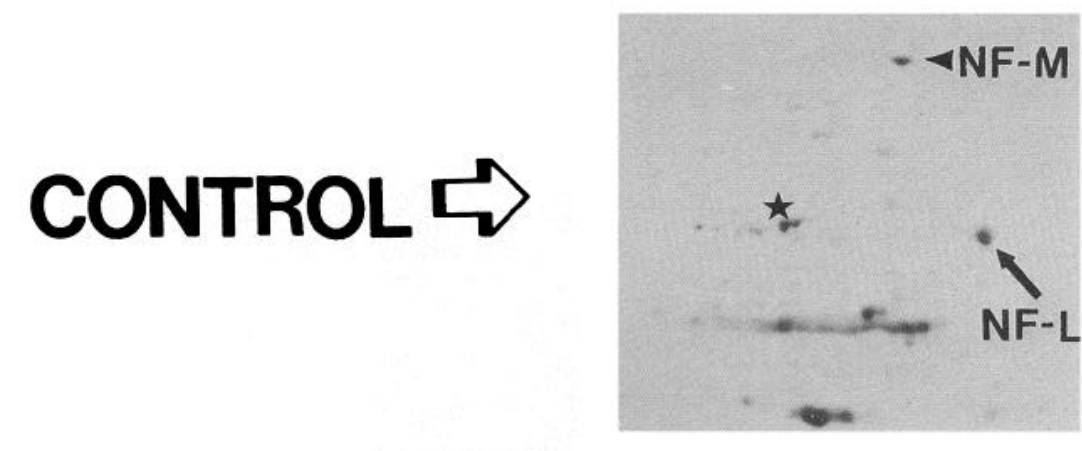

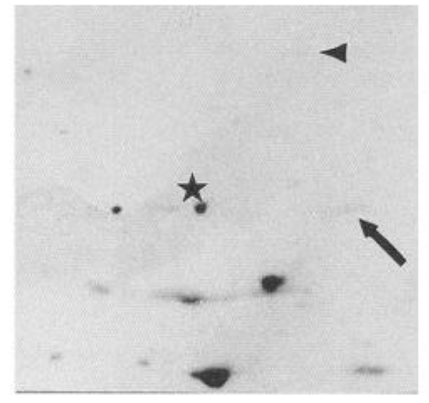

1 Day

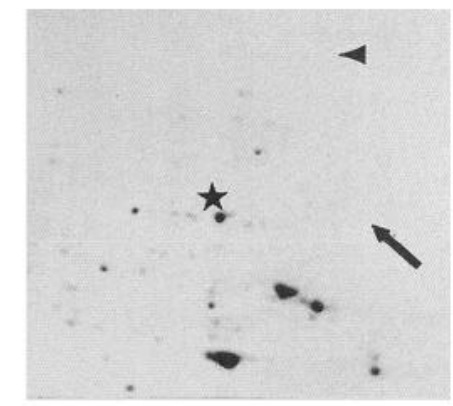

3 Day

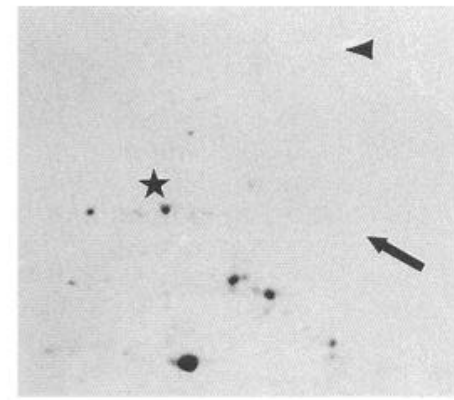

14 Day

\section{CUT}

Figure 8. Fluorographs of DRG NF-L and NF-M polypeptide expression at various time points following removal of a $2 \mathrm{~mm}$ segment from the dorsal roots (cut condition). All fluorographs shown had equal acid-precipitable cpm added to each gel. Arrows point to the position of NF-L, and arrowheads point to the position of NF-M. As in the crush-ligation condition, radiolabeling of both NF-L and NF-M appears to decrease by $1 \mathrm{~d}$ following injury and does not recover to control levels.

by the fact that the ligation does not create a complete cul-desac and many axons pass through it and reach the DRTZ and form axo-glial endings. The data obtained from this group, then, are consistent with the requirement of a physiological interaction at axonal endings for upregulating NF subunit synthesis.

Cut group. In the cut group, the dorsal roots are completely transected and a $2 \mathrm{~mm}$ segment removed. The $2 \mathrm{D}$ fluorographs in Figure 8 show that, as in the cut-ligation group, the initial decrease in NF subunit synthesis does not appear to be followed by a return to control levels. Statistical analyses of the cut data showed that synthesis of both NF subunits, at all time points following cut, was significantly different from control $(p<0.005)$. The bar histogram in Figure 9 shows that, unlike the crushligation group, there does not appear to be a trend toward control synthesis levels between 1 and $14 \mathrm{~d}$ postinjury. These data are consistent with the fact that the axons are unable to reach the DRTZ and form axo-glial endings.

Additionally, electron microscopic observations of the swollen, cut proximal ends (nearest the DRG) of the dorsal roots revealed numerous swollen axonal endings filled with NFs, mitochondria, and membranous organelles (Fig. 10). These endings are morphologically similar to those observed at ligation neuromas (see Liuzzi and Lasek, 1987a; Liuzzi, 1990b) and indicate that the physiological stop pathway is not activated in axonal endings stopped at the cut proximal ends of the roots.

\section{Discussion}

The present study shows that NF protein synthesis in the DRG following dorsal root crush and formation of axo-glial endings in the DRTZ is regulated by activation of physiological mechanisms in those endings by DRTZ astrocytes. Data from this study further support the idea that astrocytes of the DRTZ do not act as a mere physical barrier to axonal regeneration but rather exploit processes normally associated with neuron-target interactions to halt axonal growth.

When a growth cone reaches an appropriate target, a series of events is initiated that transforms the motile axonal ending into a stable presynaptic terminal. Liuzzi and Lasek (1987a) named this series of events the physiological stop pathway, and there is experimental evidence indicating that it is activated not only by neuron-target interactions but also by neuron-glial interactions in the DRTZ.

One striking ultrastructural feature of normal presynaptic terminals is that they are devoid of NFs. In vivo experiments have shown that these cytoskeletal elements are broken down in the high calcium environment of the terminals by calcium-activated proteases (Roots, 1983) that travel with NFs from the cell body to the axon terminals (Schlaepfer, 1987).

Axo-glial endings in the DRTZ are ultrastructurally similar to normal presynaptic terminals. Like those normal endings, 


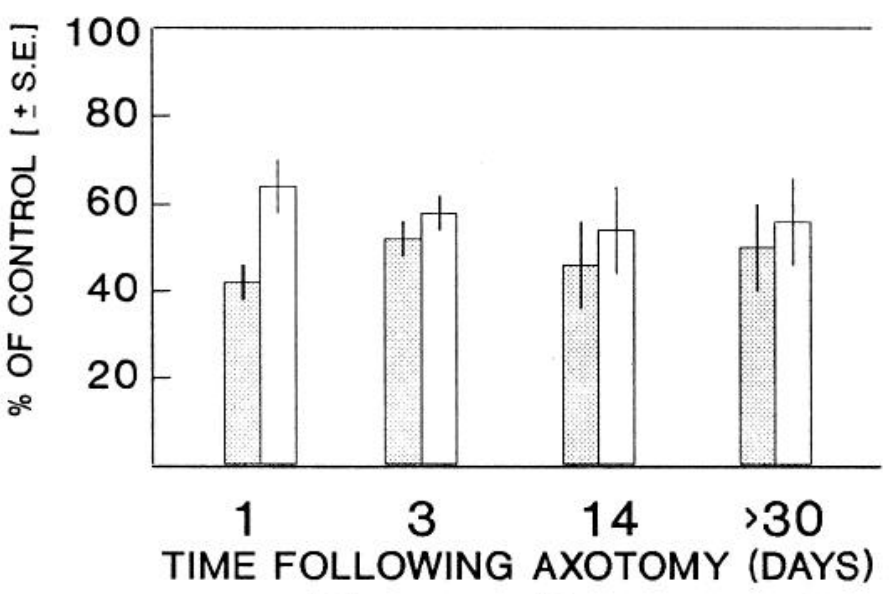

NF-L

NF-M

Figure 9. Bar histograph showing the kinetics of the quantitative changes in DRG synthesis of NF subunits in the cut condition. For either NFL or NF-M, the data points were based on three experimental gels (three animals) at $1 \mathrm{~d}$ postcut, four experimental gels (four animals) at $3 \mathrm{~d}$ postcut, three experimental gels (three animals) at $14 \mathrm{~d}$ postcut, and four experimental gels (four animals) at $>30 \mathrm{~d}$ postcut. Error bars represent SE. The quantitative data verify that, as in the crush-ligation condition, the DRG synthesis of both NF subunits did not return to control levels. However, unlike the crush-ligation condition, there was no significant change in NF recovery from 1 to $>30 \mathrm{~d}$ postinjury in the cut condition.

they are characterized by an absence of NFs (Carlstedt, 1985; Liuzzi and Lasek, 1987a), and there is evidence that the removal of NFs from axo-glial endings is by the same mechanism that operates in presynaptic terminals (Liuzzi, 1990a).

Further support for the importance of the neuron-glial interaction in the regulation of NF breakdown in axo-glial endings is provided by studies in which the regenerating axons are prevented from reaching the DRTZ by tightly ligating the root. Just as the ends of other regenerated axons swell with NFs when prevented from attaining their normal targets (Liuzzi, 1990b; Fried et al., 1991), the ends of regenerated dorsal root axons swell with NFs when deprived of contact with DRTZ astrocytes (Liuzzi and Lasek, 1987a).

Removal of NFs, then, is dependent on neuron-target interactions in the case of normal presynaptic terminals and neuronglial interactions in the case of DRTZ axo-glial endings. But what about NF synthesis? Hoffman et al. $(1985,1987)$ have proposed that NF synthesis is regulated by neuron-target interactions and that this synthesis will not return to normal levels when regenerating axons are deprived of the opportunity to reach appropriate targets. If DRTZ astrocytes are alternative targets for regenerating dorsal root axons, as suggested by the earlier studies, then they too should regulate NF synthesis.

Following axotomy of either the peripheral or central axons of DRG neurons, NF mRNA levels (Hoffman et al., 1987; Wong and Oblinger, 1987, 1990) and NF subunit synthesis (Greenberg and Lasek, 1988; Oblinger and Lasek, 1988) decline. When the regenerating peripheral axons reach their targets, synthesis of NFs, believed important for increasing axon diameter (Hoffman et al., 1984), returns to normal (Greenberg and Lasek, 1988), as do NF mRNA levels (Hoffman et al., 1987; Wong and Oblinger, 1987, 1990).

Data from the present study show that following dorsal root crushes, NF synthesis declines within $24 \mathrm{hr}$. Moreover, when
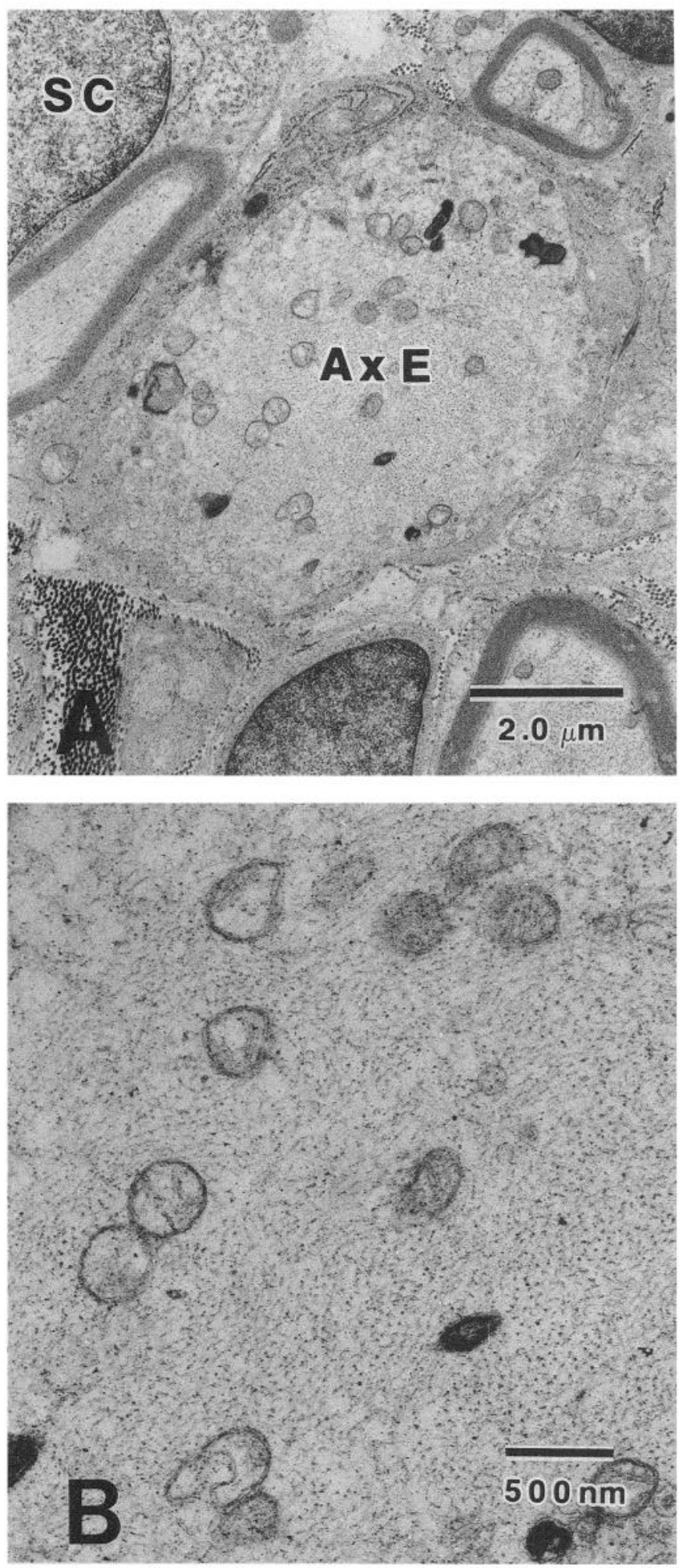

Figure 10. A, Electron microscopy of the cut proximal end of a dorsal root in the cut condition revealed numerous swollen axon endings similar to the one shown here. $A \times E$, axon ending; $S C$, Schwann cell. $B$, Higher magnification of the axonal ending shown in $A$ reveals an accumulation of NFs, mitochondria, and membranous organelles. 
the axons are allowed to reach the DRTZ and form axo-glial endings, NF-L and NF-M syntheses return to normal, control levels, as they do when regenerating peripheral sensory axons reach their targets (Greenberg and Lasek, 1988). These observations, coupled with the finding that DRG NF-L mRNA levels, which decline after dorsal root crush, return to normal when the regenerating dorsal root axons reach the DRTZ (Wong and Oblinger, 1990), support the idea that DRTZ astrocytes can regulate NF gene expression in DRG neurons.

Further evidence of this is provided by conditions in which regenerating dorsal root axons are prevented from reaching the DRTZ. Two methods were used in this study to stop the axons from reaching the DRTZ, a tightly tied ligature of the root between the crush site and the spinal cord or removal of a 2 $\mathrm{mm}$ segment of the root.

Data from this and previous studies (Liuzzi and Lasek, 1987a; Liuzzi, 1990a,b) show that either method results in axonal endings swollen by NFs. Under both conditions, NF-L and NF-M subunit syntheses never return to normal levels. Differences between the levels of NF subunit synthesis in the two conditions are explained by the observations that in the crush-ligation condition, many axons get past the ligature and continue to grow to the DRTZ, where they presumably form axo-glial endings. By contrast, in the cut condition, in which $2 \mathrm{~mm}$ of dorsal root is removed, none of the regenerating axons reach the DRTZ.

These data clearly indicate that DRTZ astrocytes regulate DRG NF-L and NF-M syntheses similarly to the way such syntheses are regulated by the dorsal root axons' normal targets within the spinal cord. The data further support the hypothesis that those astrocytes exploit the physiological stop pathway to stop axonal regeneration. The question remains as to the nature of the signal the astrocytes use to activate the stop pathway.

One possibility is that the signal is a soluble factor released by DRTZ astrocytes. There is considerable data that target tissues release soluble growth factors, such as NGF, which are taken up by axonal endings and retrogradely transported to the neuronal cell bodies (Hendry et al., 1974; Johnson et al., 1987). NGF has been shown to regulate NF gene expression in PC12 cells in vitro (Lee et al., 1982; Lindenbaum et al., 1987). Moreover, Verge et al. (1990) recently have shown that application of exogenous NGF upregulates NF gene expression in those DRG neurons with high-affinity NGF receptors following axotomy of their peripherally directed processes.

NGF alone, however, is an unlikely candidate as the signal for activation of the physiological stop pathway at the DRTZ because NGF regulates NF gene expression in only a small subpopulation of DRG neurons (Verge et al., 1990). In a large number of adult DRG neurons, NF gene expression is unaffected by NGF (Wong and Oblinger, 1991).

Soluble factors other than NGF are likely to be important to DRG ncuronal maintenance and the regulation of NF gene expression in those DRG neurons that are not NGF dependent. For example, muscle extracts, treated with an antibody to NGF, have been shown to promote the survival of large, light, NFpositive DRG neurons (Valmier et al., 1990). Moreover, insulin and insulin-like growth factors (IGFs) recently have been shown to increase NF mRNA levels in neuroblastoma cells (Wang et al., 1992). Yel, while astrocytes have been shown to express NGF (Yamakuni et al., 1987; Lu et al., 1991) and IGFs (Rotwein et al., 1988) under certain conditions, it remains to be determined whether DRTZ astrocytes express growth factors following dorsal root injury.
Alternatively, activation of the physiological stop pathway might involve surface, membrane interactions between the growing axon tips and the DRTZ astrocytes that stop axonal growth. The cell surface interaction at the transitional zone might involve the absence of a growth-permissive substrate such as laminin on the surfaces of astrocytes (Bignami et al., 1984) or the presence, on their surfaces, of an inhibitory molecule (Pindzola and Silver, 1990). Observations from the present study, however, suggest that stopping axonal growth alone is insufficient to activate the stop pathway and consequently upregulate NF protein synthesis.

Thus, a third possibility to be considered is the idea that activation of the physiological stop pathway by astrocytes at the DRTZ is a two-step process involving cell surface interactions as well as secreted, soluble factors. The axons might first be stopped at the DRTZ by changes in the substrate. Locally released growth factors might then be taken up by the stopped axonal endings and retrogradely transported to the cell body where they regulate NF gene expression.

Regardless of the signal astrocytes use to activate the stop pathway, the data from this study, coupled with that from previous ultrastructural studies (Liuzzi and Lasek, 1987a; Liuzzi, 1990a), indicate that the astrocytes of the DRTZ are not a mere physical barrier to axonal growth. Rather, those cells stop axonal regeneration by exploiting a process normally associated with synaptogenesis. Understanding how DRTZ astrocytes activate the pathway may lead to an understanding of the astrocytic role in the failure of adult mammalian CNS regeneration.

\section{References}

Bignami A, Chi NH, Dahl D (1984) Regenerating dorsal roots and the nerve entry zone: an immunofluorescence study with neurofilament and laminin antisera. Exp Neurol 85:426-436.

Bonner WM, Laskey RA (1975) A film detection method of tritiumlabeled proteins and nucleic acids in polyacrylamide gels. Eur J Biochem 46:83-88.

Carlstedt $T$ (1985) Regenerating axons form terminals at astrocytes. Brain Res 347:188-191.

David S, Aguayo AJ (1981) Axonal elongation into peripheral nervous system "bridges" after central nervous system injury in adult rats. Science 246:255-258.

Fried K, Govin-Lippmann R, Rosenthal F, Ellisman MH, Devor M (1991) Ultrastructure of afferent axon endings in a neuroma. J Neurocytol 20:682-701.

Greenberg SG, Lasek RJ (1988) Neurofilament protein synthesis in DRG neurons decreases more after peripheral axotomy than after central axotomy. J Neurosci 8:1739-1746.

Hall ME (1982) Changes in synthesis of specific proteins in axotomized dorsal root ganglia. Exp Neurol 76:83-93.

Hendry IA, Stockkel K, Thoenen H, Iverson LL (1974) Retrograde axonal transport of nerve growth factor. Brain Res 68:103-121.

Hoffman PN, Griffin JW, Price DL (1984) Control of axonal caliber by neurofilament transport. J Cell Biol 99:705-714.

Hoffman PN, Thompson GW, Griffin JW, Price DL (1985) Changes in neurofilament transport coincide temporally with alteration in the caliber of axons in regenerating motor fibers. J Cell Biol 101:13321340.

Hoffman PN, Cleveland DW, Griffin JW, Landes PW, Cowan NJ, Price DL (1987) Neurofilament gene expression: a major determinant of axonal caliber. Proc Natl Acad Sci USA 84:3472-3476.

Johnson EM, Taniuchi M, Clark HB, Springer JE, Koh S, Tayrien MW, Loy R (1987) Demonstration of retrograde transport of nervegrowth factor receptor in the peripheral and central nervous system. J Neurosci 7:923-929.

Laskey RA, Mills AD (1975) Quantitative film detection of ${ }^{3} \mathrm{H}$ and ${ }^{14} \mathrm{C}$ in polyacrylamide gels by fluorography. Eur J Biochem 56:335-341.

Lee V, Trajanowski JQ, Schlaepfer WW (1982) Induction of neurofilament triplet in PC1 2 cells by nerve growth factor. Brain Res 238: 169-180. 
Liesi P (1985) Laminin-immunoreactive glia distinguish regenerative adult systems from non-regenerative ones. EMBO J 4:2505-2511.

Lindenbaum MH, Carbonetto S, Mushyski WE (1987) Nerve growth factor enhances the synthesis, phosphorylation, and metabolic stability of neurofilament proteins in PC12 cells. J Biol Chem 262:605610.

Liuzzi FJ (1990a) Proteolysis is a critical step in the physiological stop pathway: mechanisms involved in the blockade of axonal regeneration by mammalian astrocytes. Brain Res 512:277-283.

Liuzzi FJ (1990b) Regulation of axonal growth through the dorsal root transitional zone in adult mammals. Adv Neural Regen Res 60:225236.

Liuzzi FJ, Lasek RJ (1987a) Astrocytes block axonal regeneration by activating the physiological stop pathway. Science 237:642-645.

Liuzzi FJ, Lasek RJ (1987b) Some dorsal root axons regenerate into the adult rat spinal cord: an HRP study. Soc Neurosci Abstr 13:395.

Lu B, Yokoyama M, Dreyfus CF, Black IB (1991) NGF expression in actively growing brain glia. J Neurosci 11:318-326.

Oblinger MM (1987) Characterization of posttranslational processing of the mammalian high-molecular-weight neurofilament protein in vivo. J Neurosci 7:2510-2521.

Oblinger MM, Lasek RJ (1988) Axotomy-induced alterations in the synthesis and transport of neurofilaments and microtubules in dorsal root ganglion cells. J Neurosci 8:1747-1758.

O'Farrell P (1975) High resolution two-dimensional electrophoresis of proteins. J Biol Chem 250:4007-4024.

Pindzola RR, Silver J (1990) The molecular environment of the dorsal root entry zone during development and after root crushes. Soc Neurosci Abstr 16:164.

Reier PJ, Houle JD (1988) The glial scar: its bearing on axonal elongation and transplantation approaches to CNS repair. Adv Neurol 47:87-138.

Richardson PM, Issa VMK, Aguayo AJ (1984) Regeneration of long spinal axons in the rat. J Neurocytol 13:165-182.

Roots BI (1983) Neurofilament accumulation induced in synapses by leupeptin. Science 221:971-972.

Rotwein P, Burgess SK, Mibrant JD, Krause JE (1988) Differential expression of insulin-like growth factor genes in rat central nervous system. Proc Natl Acad Sci USA 85:265-269.

Schlaepfer WW (1987) Neurofilaments: structure, metabolism and implications in disease. J Neuropathol Exp Neurol 46:117-129.

Schnell L, Schwab ME (1990) Axonal regeneration in the rat spinal cord produced by an antibody against myelin-associated neurite growth inhibitors. Nature 343:269-272.

Schwab ME, Caroni P (1988) Oligodendrocytes and CNS myelin are nonpermissive substrates for neurite growth and fibroblast spreading in vitro. J Neurosci 8:2381-2393.
Siensaus LJ, Partlow LM, Burgess PR, Horch KW (1987) Inhibition of regeneration: the ultrastructure of reactive astrocytes and abortive axon terminals in the transitional zone of the dorsal root. Prog Brain Res 71:457-468.

Tedeschi B, Wilson DL (1983) Modification of a rapidly transported protein in regenerating nerve. $J$ Neurosci $3: 1728-1734$.

Tedeschi B, Wilson DL (1987) Subsets of axonally transported and periaxonal polypeptides are released from regenerating nerve. J Neurochem 48:463-469.

Tetzlaff W, Bisby MA, Kreutzberg GW (1988) Changes in cytoskeletal proteins in the rat facial nucleus following axotomy. J Neurosci 8: 3181-3189.

Valmier J, Tafti M, Baldy-Moulinier M (1990) Skeletal muscle extracts promote the survival of neurofilament-positive mammalian sensory neurons. Neurosci Lett 1 1:39-44.

Verge VMK, Tetzlaff W, Bisby MA, Richardson PM (1990) Influence of nerve growth factor on neurofilament gene expression in mature primary sensory neurons. J Neurosci 10:2018-2025.

Vidal-Sanz M, Bray GM, Villegas-Perez MP, Thanos S, Aguayo AJ (1987) Axonal regeneration and synapse formation in the superior colliculus by retinal ganglion cells in the adult rat. J Neurosci 7:2894 2909.

Wang C, Li Y, Wible B, Angelides KJ, Ishii DN (1992) Effects of insulin and insulin-like growth factors on neurofilament mRNA and tubulin mRNA content in human neuroblastoma SH-SY5Y cells. Mol Brain Res 13:289-300.

Wilson DL, Hall ME, Stone GC, Rubin RW (1977) Some improvements in two-dimensional gel electrophoresis of proteins. Anal Biochem 86:33-34.

Wong J, Oblinger MM (1987) Changes in neurofilament gene expression occur after axotomy of dorsal root ganglion neurons: an in situ hybridization study. Metab Brain Dis 2:291-303.

Wong J, Oblinger MM (1990) A comparison of peripheral and central axotomy effects on neurofilament and tubulin gene expression in rat dorsal root ganglion neurons. J Neurosci 10:2215-2222.

Wong J, Oblinger MM (1991) NGF rescues substance P expression but not neurofilament or tubulin expression in axotomized sensory neurons. J Neurosci 11:543-552.

Wujek JR, Lasek RJ (1983) Correlation of axonal regeneration and slow component $B$ in two branches of a single axon. $J$ Neurosci 3: 243-251.

Yamakuni T, Ozawa F, Hishinuma F, Kuwano R, Takahashi Y, Amano $T$ (1987) Expression of $\beta$-nerve growth factor mRNA in rat glioma cells and astrocytes from rat brain. FEBS Lett 223:117-121. 